\title{
Reply to: Parker A. Comment on "Low-frequency sea level variation and its correlation with climate events in the Pacific"
}

\author{
JIN TaoYong ${ }^{1,2}$, LI JianCheng $^{1,2}$, JIANG WeiPing $^{1 *} \&$ CHU YongHai ${ }^{1,2}$ \\ ${ }^{1}$ School of Geodesy and Geomatics, Wuhan University, Wuhan 430079, China; \\ ${ }^{2}$ Key Laboratory of Geospace Environment and Geodesy, Ministry of Education, Wuhan 430079, China
}

Received October 25, 2012; accepted December 25, 2012; published online March 26, 2013

First, we would like to thank Parker for his discussion and comments on our work. Parker's main concern [1] is that the sea level is oscillating with important multi-decadal periodicities but absolutely not positively accelerating. He also argued that the global mean sea level (GMSL) acceleration computed by Jin et al. [2] seemed too large. His similar concern had also appeared in the comment of local sea level rise on Long Island, New York [3]. The most important difference between these two commented papers is that the former computes the sea level acceleration globally, while the latter locally. Parker quoted both, individual tide gauges and the time series of GMSL by satellite radar altimeter from the University of Colorado CU Sea Level Research Group.

Individual tide-gauge records with enough length and quality can be used to compute the local sea level accelerating trend. However, the length should be longer than 60 years [4] to avoid large oscillations due to long-term tidal effects, which has also been confirmed by Parker himself [5]. As we known, individual tide-gauge records only represent the mean sea level variation within localized area. Parker presented the sea level records of several tide gauges in his Figure 1. The length of sea level time series are all longer than 100 years, and the 2nd order coefficients computed from the time series have both positive and negative values. The results show the largest positive acceleration in San Francisco, CA of $+0.007 \mathrm{~mm} / \mathrm{a}^{2}$, and the largest negative acceleration in Honolulu, $\mathrm{HI}$ of $-0.006 \mathrm{~mm} / \mathrm{a}^{2}$. These phenomena demonstrate that the local sea levels are accelerating or decelerating in different sea areas. Nevertheless, the GMSL accelerating trend is still unknown from his Figure 1. Either by tide gauges, or by satellite radar altimetry, many researches have achieved the conclusion that regional mean sea level trends are geographically dependent. Wood-

*Corresponding author (email: wpjiang@whu.edu.cn) worth et al. [6] had pointed out that most of the tide-gauge data from Europe and North America display evidence for a positive acceleration, but the magnitude of the acceleration varies between stations. There are also a few of stations which display negative accelerations. From the most recent results published by AVISO (http://www.aviso.oceanobs.com/ en/news/ocean-indicators/mean-sea-level/) and that shown in Figure 1, we can see large difference, especially between eastern and western parts of the Pacific Ocean. Another fact is that the magnitude of the acceleration/deceleration depends on the time period of observations.

For comparison, we select the tide gauges whose periods are longer then 60 years from the Revised Local Reference (RLR) dataset provided by PSMSL (http://www.psmsl.org/ data/obtaining/) [7], and remove the tide gauges whose spare time is greater then $30 \%$ to ensure the stability. Then considering the seasonal signals, the sea level records on each selected tide gauge are fitted by the following linear regression model:

$$
\begin{aligned}
y= & a+b t+c t^{2}+d \cos (2 \pi t)+e \sin (2 \pi t)+f \cos (4 \pi t) \\
& +g \sin (4 \pi t),
\end{aligned}
$$

where $y$ is the sea level record, $t$ is the observed time, $a$ is

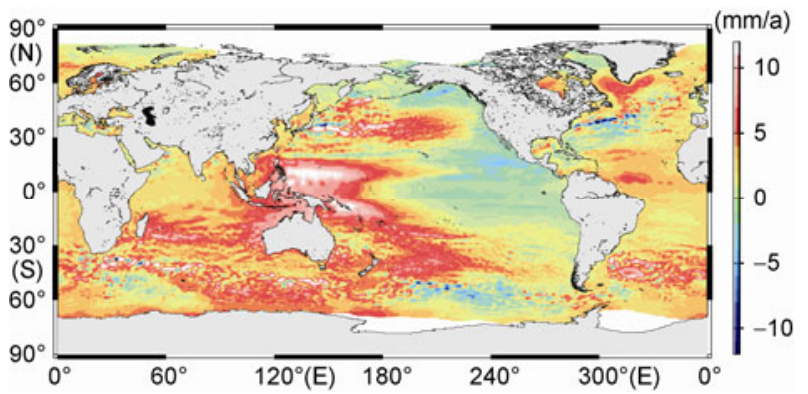

Figure 1 Regional mean sea level trends from Oct 1992 to Apr 2012. 
the residual bias, $b$ is the rate of sea level change, $c$ is the accelerating rate of sea level change, $d, e$ are the annual cycle parameters of sea level change, $f, g$ are the semi-annual cycle parameters of sea level change.

The number of the selected tide gauges is 226 , among which, there are 84 stations having negative accelerating rates (Figure 2(a)) and 142 stations having positive accelerating rates (Figure 2(b)). If we simply average the accelerating rates on all stations, the global mean accelerating rate is $0.005 \mathrm{~mm} / \mathrm{a}^{2}$. Since the distribution of the tide gauges with period longer than 60 years is very sparse in global ocean, to obtain the trend of GMSL by tide gauges, one should firstly divide all valid tide gauges into several geographic groups, and then average the sea level trends from tide gauges in each group, and finally, average the group mean trends globally [4]. So, we apply the weighted average by the fitting error of each station in each $10^{\circ} \times 10^{\circ}$ cell firstly, and then the global mean accelerating rate is achieved to be $0.012 \mathrm{~mm} / \mathrm{a}^{2}$ by averaging the values of all cells in globe. Also from the pure tide gauge data, Jevrejeva et al. [8] provided evidence that global sea level acceleration up to the present was about $0.010 \mathrm{~mm} / \mathrm{a}^{2}$ and appeared to have started at the end of the 18th century; Woodworth et al. [9] pointed out that an acceleration was indeed observed in both tide gauge and saltmarsh data at different locations around the world, yielding quadratic coefficients of order 0.005 $\mathrm{mm} / \mathrm{a}^{2}$, with the most rapid changes rate of the sea level rise occurring around the end of the 19th century. All these results are consistent with our result within the error range [2].

Even if the tide-gauge data are averaged in global scale for a particular month to obtain the GMSL time series, the
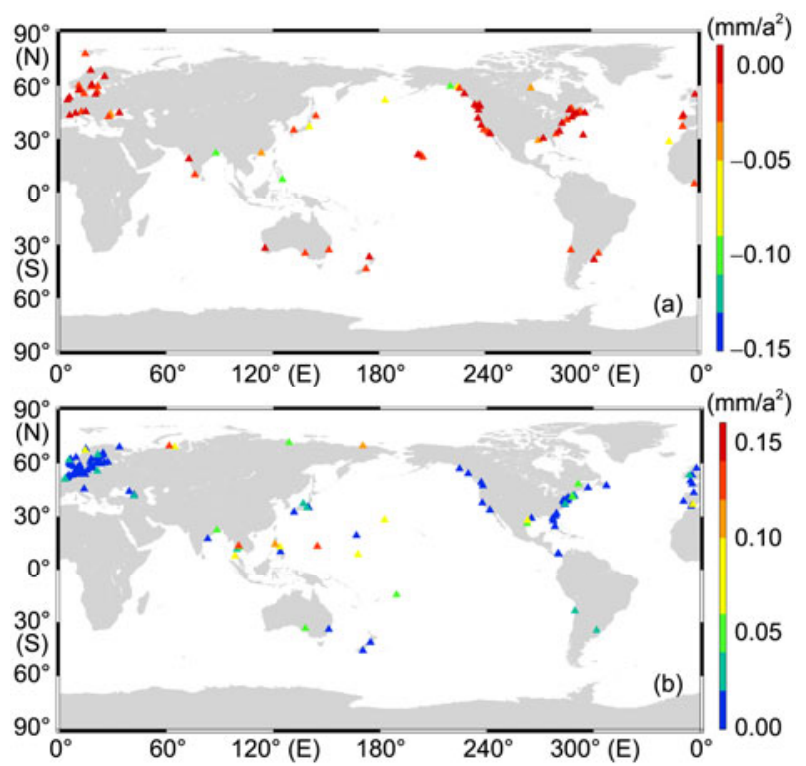

Figure 2 Distribution and sea level accelerating rates of tide gauges with period longer than 60 years. (a) The 84 tide gauges that have negative accelerating rate; (b) 142 tide gauges that have positive accelerating rate. result shows a much larger seasonal variations than that observed by satellite altimetry during the same interval. If the seasonal signal is removed from tide-gauge data, the obtained GMSL time series still does not measure the same variability as observed by satellite altimetry [10]. The time series of GMSL computed by simply average or weighted average using regional groups of tide-gauge data only represent coastal and island sea level change, but not the open ocean sea level change. Another approach to determine the time series of GMSL is to combine the globally distributed satellite altimeter data together with the coastal and island tide-gauge data. This approach was first developed by Chambers et al. [10] for inter-annual sea level variability and extended by Church et al. [11] to examine sea level trends. Many researchers reconstructed the historical time series of GMSL change using this approach, but with various sets of EOFs [12-15]. All of them confirmed the possibility and stability of this approach through comparisons between the reconstructed GMSL trend and the results from tide gauge or satellite altimetry individually, but few of them discussed the accelerations. Among these researchers, Church and White $[16,17]$ updated their reconstructions to estimate the GMSL trend in the period of 1880 to the present, and the significant accelerations of $0.013 \pm 0.006 \mathrm{~mm} / \mathrm{a}^{2}$ and $0.009 \pm 0.004 \mathrm{~mm} / \mathrm{a}^{2}$ during the 20th century were detected respectively, which are also consistent with our result within the error range [2].

Another dataset used in the comment is the GMSL time series by satellite altimeter data from 1993 to the present. Using the GMSL time series, Parker computed the 2nd order coefficients of $-0.006 \mathrm{~mm} / \mathrm{a}^{2}$ to show a negative acceleration. However, Niedzielski and Kosek [18] pointed out that over the GMSL time series from T/P, Jason-1 and Jason-2 altimeter observations of the period from January 1993 to April 2010, it was impossible to detect any acceleration in sea level rise with probability close to 1 . Expect for only two exceptions, when the time spans are approximately 400 and 500 satellite cycles, acceleration can be detected with at least 0.4 probability. That is to say, using short period of time series, the accelerating trend of GMSL is hard to detect.

Due to the lack of globally distributed sea level data with enough length and quality, it is now still controversial whether the GMSL is accelerating or not. This is also the reason why so many researches seek for the combination of tide gauge and satellite altimeter data. But, some problems in the reconstruction still need to be solved and the uncertainty is still large. For instance, the lower spatial resolution of grid sea level change by satellite altimetry data, the datum inconsistency of tide gauges, the sparseness of tide gauges in early years, and so on. All of these problems should be carefully considered to obtain precise and stable GMSL time series with enough length to detect the accelerating trend in future. 
The authors thank two anonymous reviewers for their valuable comments on the paper, and Prof. Shen W B and Prof. Robert Tenzer for their helpful advice. This work was supported by the National Basic Research Program of China (2012CB957703) and the National Natural Science Foundation of China (41210006).

1 Parker A. Comment on "Low-frequency sea level variation and its correlation with climate events in the Pacific". Chin Sci Bull, 2013, 58: 1708-1713

2 Jin T Y, Li J C, Jiang W P, et al. Low-frequency sea level variation and its correlation with climate events in the Pacific. Chin Sci Bull, 2012, 57: 3623-3630

3 Parker A. Comment to Shepard C C, Agostini V N, Gilmer B, Allen T, Stone J, Brooks W, Beck M W: Assessing future risk: Quantifying the effects of sea level rise on storm surge risk for the southern shores of Long Island New York, Natural Hazards, 2012, 60: 727-745. Nat Hazards, 2013, 65: 977-980

4 Douglas B C. Global sea level acceleration. J Geophys Res, 1992, 97 : 12699-12706

5 Parker A. Sea level trends at locations of the United States with more than 100 years of recording. Nat Hazards, 2013, 65: 1011-1021

6 Woodworth P L, White N J, Jevrejeva S, et al. Evidence for the accelerations of sea level on multi-decade and century timescales. Int $\mathrm{J}$ Climatol, 2009, 29: 777-789

7 Woodworth P L, Player R. The permanent service for mean sea level: An update to the 21st century. J Coastal Res, 2003, 19: 287-295

8 Jevrejeva S, Moore J C, Grinsted A, et al. Recent global sea level acceleration started over 200 years ago. Geophys Res Lett, 2008, 35:
L08715

9 Woodworth P L, Menendez M, Gehrels W R. Evidence for centurytime scale acceleration in mean sea levels and for recent changes in extreme sea levels. Surv Geophys, 2011, 32: 603-618

10 Chambers D P, Mehlhaff C A, Urban T J, et al. Low-frequency variations in global mean sea level: 1950-2000. J Geophys Res, 2002, 107: 3026

11 Church J A, White N J, Coleman R, et al. Estimates of the regional distribution of sea level rise over the 1950-2000 period. J Clim, 2004, 17: 2609-2625

12 Wenzel M, Schröter J. Reconstruction of regional mean sea level anomalies from tide gauges using neural networks, J Geophys Res, 2010, 115: C08013

13 Ray, R D, Douglas B C. Experiments in reconstructing twentiethcentury sea levels. Prog Oceanogr, 2011, 91: 496-515

14 Hamlington B, Leben R, Nerem R S, et al. Reconstructing sea level using cyclostationary empirical orthogonal functions. J Geophys Res, 2011, 116: C12015

15 Meyssignac B, Becker M, Llovel W, et al. An assessment of two-dimensional past sea level reconstructions over 1950-2009 based on tide-gauge data and different input sea level grids. Surv Geophys, 2012, 33: 945-972

16 Church J A, White N J. A 20th century acceleration in global sealevel rise. Geophys Res Lett, 2006, 33: L01602

17 Church J A, White N J. Sea-level rise from the late 19th to the early 21st century. Surv Geophys, 2011, 32: 585-602

18 Niedzielski T, Kosek W. Minimum time span of TOPEX/Poseidon, Jason-1 and Jason-2 global altimeter data to detect a significant trend and acceleration in sea level change. Adv Space Res, 2011, 47: 12481255

Open Access This article is distributed under the terms of the Creative Commons Attribution License which permits any use, distribution, and reproduction in any medium, provided the original author(s) and source are credited. 